\title{
Hidden colours in stuccowork damaged by fire: a multi-analytical investigation for revealing the original decorative pattern
}

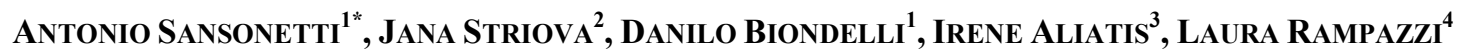 \\ ${ }^{1}$ National Research Council (CNR), Istituto per la Conservazione e la Valorizzazione dei Beni Culturali, Via R. Cozzi 53, 20125 \\ Milan (Italy) \\ ${ }^{2}$ National Research Council (CNR), Istituto Nazionale di Ottica, Università di Firenze, Via Nello Carrara 1, 50019 Sesto Fiorentino \\ (Italy) \\ ${ }^{3}$ Dipartimento di Fisica e Scienze della Terra, Università di Parma, Parco Area delle Scienze 7/A, 43124 Parma (Italy) \\ ${ }^{4}$ Dipartimento Scienza e Alta Tecnologia, Università dell'Insubria, via Valleggio 11, 22100 Como (Italy)
}

*Corresponding author.

Antonio Sansonetti, email address: sansonetti@icvbc.cnr.it; phone number: +39 0266173342

\begin{abstract}
The finishes applied on stuccoworks deserves in-depth analytical investigations. A complete chemical and morphological survey is very useful in reconstructing the artist's technique, the history of the artworks through the sequence of the applied layers, and is needed as a basis for any conservation approach. Microscopic observations, both optical and electronic (SEM), and spectroscopic analyses ( $\mu$ Raman, $\mu F T I R$ and EDS) of gilded and polychrome finishes on plaster relieves, were carried out on 17 samples from a celebrated neoclassical hall in the Royal Palace of Milan (Hall of Caryatids). The original decorative pattern had been damaged during a bomb-induced fire in the Second World War. Most of the surfaces have been fatally compromised and blackened by the effects of the fire. The survey presented here analysed the materials constituting the stucco surfaces and the damage induced by the fire. Green pigments were individuated and mapped, although no green surfaces were visible to the naked eye. It was therefore possible to reconstruct a decorative pattern painted in green, gold and white, similar to traditions of decoration in Austria and southern Germany.
\end{abstract}

Keywords: $\mu$-Raman, $\mu$-FTIR, fire damage, plaster gildings, coloured grounds, chrome green 


\section{Introduction}

Gilts are among the most common decorative finishes on architectural elements, painting details, and art objects. Several manuals provided instructions regarding their execution technique [1,2]. The compositional and morphological characterization of gilts is very useful in the reconstruction of the historical and technical assessment of the artwork and in the selection of restoration treatments, such as cleaning, integration of the missing parts, and consolidation [3].

A few authors examined the technical execution of gilt on plaster surfaces $[4,5,6]$, nevertheless their wide spread on historical buildings. These studies highlight that mordant gilding prevailed over other techniques (water gilding on bole, gold in powder mixed with mineral charges) in the decoration of plaster surfaces [7].

This paper focus on a vast neoclassical ballroom in the Milan Royal Palace (Hall of Caryatides), with an examination of the gilt remnants and their grounds, and of the finishes applied on adjacent plaster elements blackened by the fire due to bombing during the Second World War. Fire and bombing are a serious threat to the cultural heritage. When architectural decorations are involved in a fire, decisions regarding the possible reconstruction are challenging. The first step involves fully understanding the changes induced by the fire and by the local temperature increases.

Three techniques, used in combination were effective in revealing the composition and morphology behind the gilt remnants. $\mu$ Raman spectroscopy, known for its spatial and spectral resolution, can probe the pigment particles and differentiate their spectral response from the surrounding matrix. Another advantage is easy access to the low wavenumber region. FTIR contributes with the investigation of the organic compounds. SEM-EDS, beside the basic knowledge of the elemental composition and its distribution, helps by providing morphological and dimensional information on the examined layers.

\section{Materials and methods}

\subsection{Materials and historical notes}

In the $18^{\text {th }}$ century the Hall of Caryatids in the Milan Royal Palace was the greatest ballroom in Europe, decorated with neoclassical plaster-works consisting of a sequence of forty caryatids. Gilded mouldings, capitals and frames adorned the hall. In this interior important plasterers, such as Albertolli, worked under the direction of the architect Piermarini. 
The Royal Palace was damaged during bombing in 1943. The damage was repaired in the post-war period, and the stucco surfaces have been conserved at different steps: the general aspect of the Hall recalls ruins and the artworks are missing many parts. The fire caused by the bomb led to the loss of the decorative pattern. Most of the relieves have blackened surfaces, whose level of blackening depends on the distance from the combustion nucleus. The black layers hide the original colours of the ornaments apart from the gold leaf remnants (Fig. 1a, 1b).
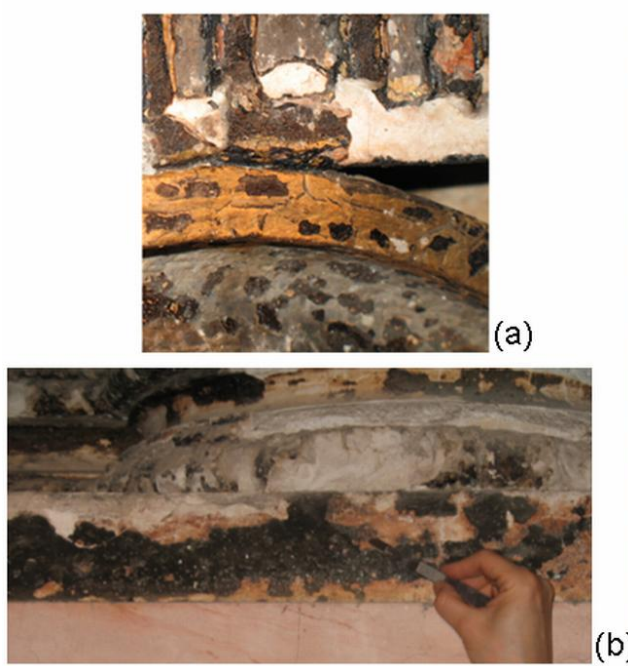

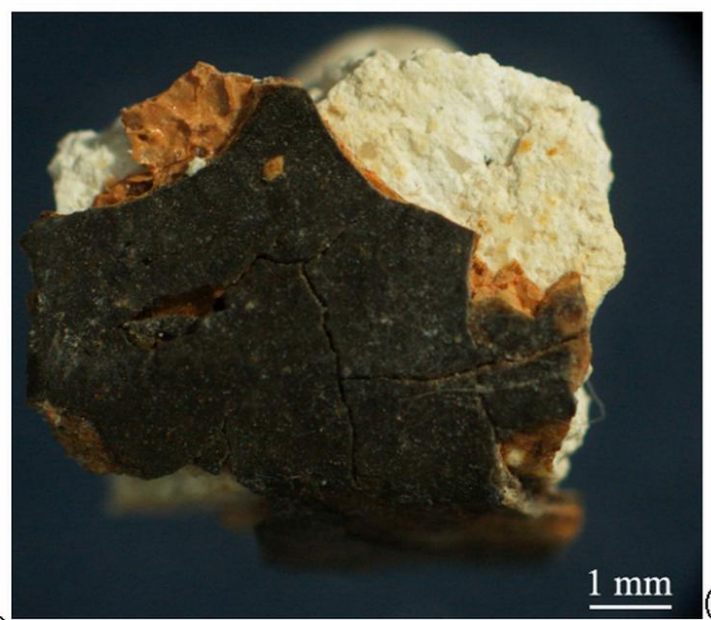

b)

Fig. 1: View of the examined surfaces showing gilt remnants (a), blackened surfaces $(\mathrm{a}, \mathrm{b})$ and details of a sample coming from a black surface (c).

\subsection{Samples}

17 micro-fragments were sampled from the gilt stucco elements, such as the column's base, capitals and mirror frames.

\subsection{Analytical methods}

Samples were observed with a Leitz Wild M420 stereomicroscope, then embedded into epoxy resin; Cross sections were examined in reflected light using a Leitz Ortholux microscope with Ultropack illuminator and a digital capture system.

Raman micro-spectroscopy was performed with a Senterra $\mu$-Raman spectrometer (Bruker) coupled to an Olympus BX51 microscope using $785 \mathrm{~nm}$ light (maximum power $100 \mathrm{~mW}$, cut off at $100 \mathrm{~cm}^{-1}$ by an edge filter). The laser beam was focused on the pigments grains using $20 \times$ (numerical aperture $\mathrm{NA}=0.40)$ and $50 \times(\mathrm{NA}=0.75)$ Olympus objectives. Raman signals were detected with a Peltier cooled CCD detector $(1024 \times 255$ pixels $)$ operating at $-70^{\circ} \mathrm{C}$. The laser power 
at the sample surface, was about $1 \mathrm{~mW}$. The spectra were collected in $100-2500 \mathrm{~cm}^{-1}$ range (spectral resolution $\sim 3 \mathrm{~cm}^{-}$

$\left.{ }^{1}\right)$. The acquisition time was 30-60 seconds according to the signal to noise ratio, repeated 6-10 times.

FTIR spectra were recorded using a Nicolet spectrophotometer combined with a Continu um microscope and a Graseby Specac diamond cell. Spectra were acquired in transmission mode $\left(4000-700 \mathrm{~cm}^{-1} ; 128 \mathrm{scans}\right.$; resolution $\left.4 \mathrm{~cm}^{-1}\right)$.

Back-scattered images, micro-beam EDS analyses and X-ray maps were collected on carbon coated polished crosssections with a JEOL 5910LV SEM system (IXRF Systems). Qualitative EDS spectra of areas or spots and elemental maps were registered from 0 to $20 \mathrm{keV}$ and at $1-3 \times 10^{-7} \mathrm{~A}$.

\section{Results}

To facilitate the interpretation of the data, the results were divided into two groups: (a) gilts, containing fragments with a single or two distinct and subsequent gold leaves, and (b) blackened surfaces. Two representative samples are described in Tables 1 and 2 .

Table 1: Stratigraphy of a representative gilt element (Figure 2)

\begin{tabular}{cll}
\hline Layer & Description & Composition \\
\hline 5 & Gilt & gold \\
4 & yellow grayish ground & yellow ochre, lead white, hematite, oil \\
3 & Gilt & gold \\
2 & white yellowish ground & yellow ochre, lead white, oil \\
1 & orange/deep yellow ground & yellow ochre, lead white, red lead, oil \\
& stucco body & gypsum and magnesite \\
\hline
\end{tabular}

Table 2: Stratigraphy of a representative blackened surface with green pigments (Figure 3)

\begin{tabular}{cll}
\hline Layer & Description & Composition \\
\hline 4 & blackened surface & partially decomposed oil, Prussian blue, lead carbonate, barite \\
3 & dark green & Prussian blue, chrome yellow, lead white, barite, ochres, oil \\
2 & light green & green earth, yellow ochre, lead white, oil \\
1 & yellow stucco finish & lead white, oil \\
& Stucco body & magnesian lime and limestone powder \\
\hline
\end{tabular}




\subsection{Gilts}

The gilts had originally been applied on small ornaments such as egg shaped elements, acanthus leaves on the capitals, fillets at the base of the columns. Examinations of the cross-sections under the optical microscope revealed a stratigraphy consisting of up to five layers. The older gilts were placed on a double-layer ground: an orange or deep yellow layer directly on the stucco body $(1$, Fig. 2), composed of red particles in a yellowish matrix, and a light yellow one (2, Fig. 2). The first layer was applied to cover the stucco body, the orange pigment particles helped to warm up the gold leaf hue. The white yellowish ground was applied as an underlying ground for the gold leaf (3, Fig. 2). In double gilt elements, a yellowish ground (4, Fig. 2) separated the two leaves, suggesting that the gilts were applied at different times and the latter leaf $(5$, Fig. 2) was probably applied during a conservation work.
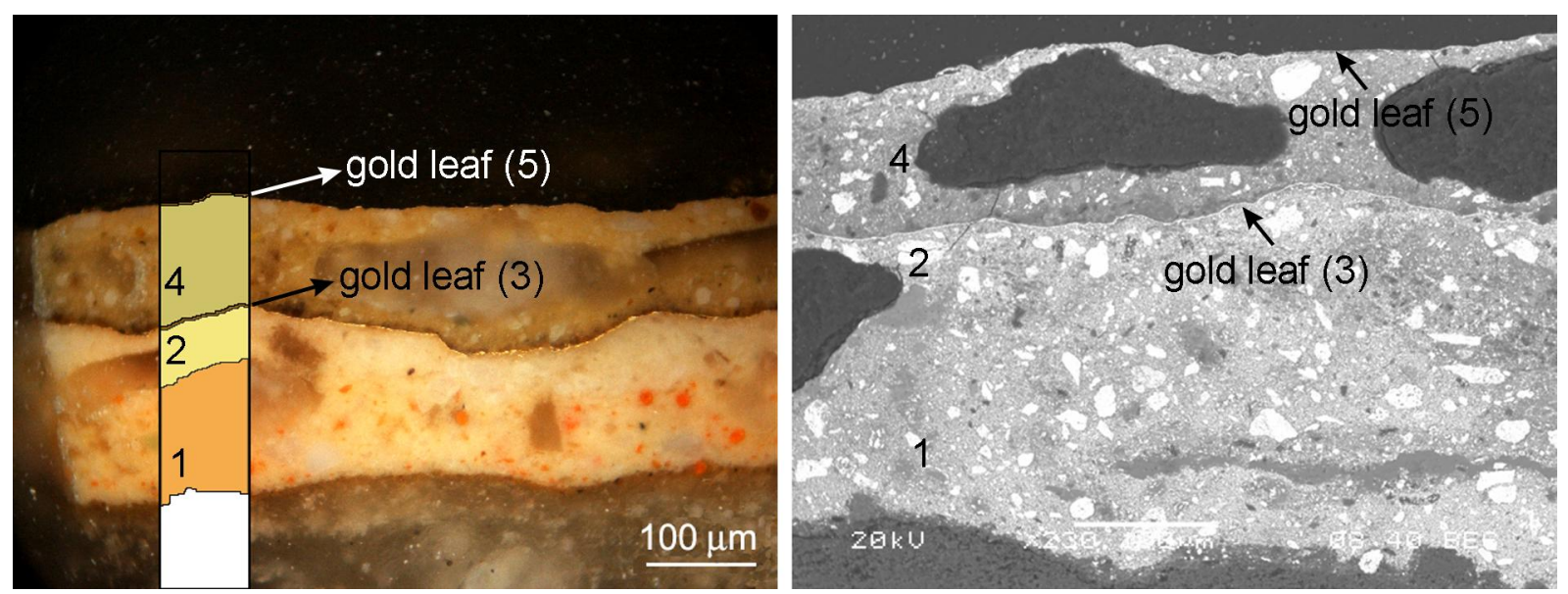

Fig. 2: Cross section with double gilt layer (3 and 5) observed under optical (a) and electron (BES) (b) microscope; bar= $120 \mu \mathrm{m}$. Back scattered electrons.

The gold leaves had a thickness of around one micron. EDS elemental analyses indicated gold as the sole element; no copper or silver were detected.

In both the inner ground layers (1 and 2, Fig. 2), yellow ochre and lead white were detected. Raman spectra of the yellow particles displayed bands at $299,388,549 \mathrm{~cm}^{-1}$, attributable to goethite, $(\alpha-\mathrm{FeOOH})$, the main component of yellow ochre, and a weak band at $1050 \mathrm{~cm}^{-1}$, attributable to $\mathrm{v}_{\mathrm{s}}\left(\mathrm{CO}_{3}{ }^{2-}\right)$ of lead white [8]. When mixed with siccative oils, saponification reactions produce lead soaps. Because of its excellent workability, this mix is suitable for the gold leaf and for burnishing. 
Red lead allowed to distinguish layers 1 and 2 and was responsible for the orange tone of the layer 1. In fact, Raman spectra collected on the red particles of layer 1 (Fig. 2) displayed bands at 122, 152, 228, 312, 391, $550 \mathrm{~cm}^{-1}$ which are characteristic of red lead $\left(\mathrm{Pb}_{3} \mathrm{O}_{4}\right)$, used since antiquity as a natural occurring mineral. The uppermost gilt was applied on a yellowish ground layer (layer 4, Fig. 2) of a similar composition to the possibly original ground: yellow ochre and lead white. The small red particles were, in this case, identified as hematite $\left(\alpha-\mathrm{Fe}_{2} \mathrm{O}_{3}\right)$, according to its characteristic Raman lines at 222, 294, 409, 497, $609 \mathrm{~cm}^{-1}$. The weak $660 \mathrm{~cm}^{-1}$ line might have had a different origin: it is attributed to a disorder-activated mode in the hematite crystalline structure, or to magnetite traces $\left(\mathrm{Fe}_{3} \mathrm{O}_{4}\right)$. The latter scattering could also be attributed to the partial thermal transformation of hematite to magnetite under reducing conditions occurring around $250{ }^{\circ} \mathrm{C}[9]$.

\subsection{Blackened surfaces}

Some of the finishes, exhibited a stratigraphy (Fig. 3), with a morphology complicated by the heat and which contained bubbles, voids, and detachments. The analyses revealed no gold leaf and no substance that might suggest the presence of a fake gilt. Instead, several superimposed green layers (layers 2 and 3, Fig. 3), between the yellow stucco finish (layer 1, Fig. 3) and the blackened surface (layer 4, Fig. 3) were detected. Green layers underneath were lighter in colour than the upper ones. Some of the samples, were completely blackened in each of the layers (Fig. 1c), suggesting the differentiated influence of the heat based on the distance from the fire.
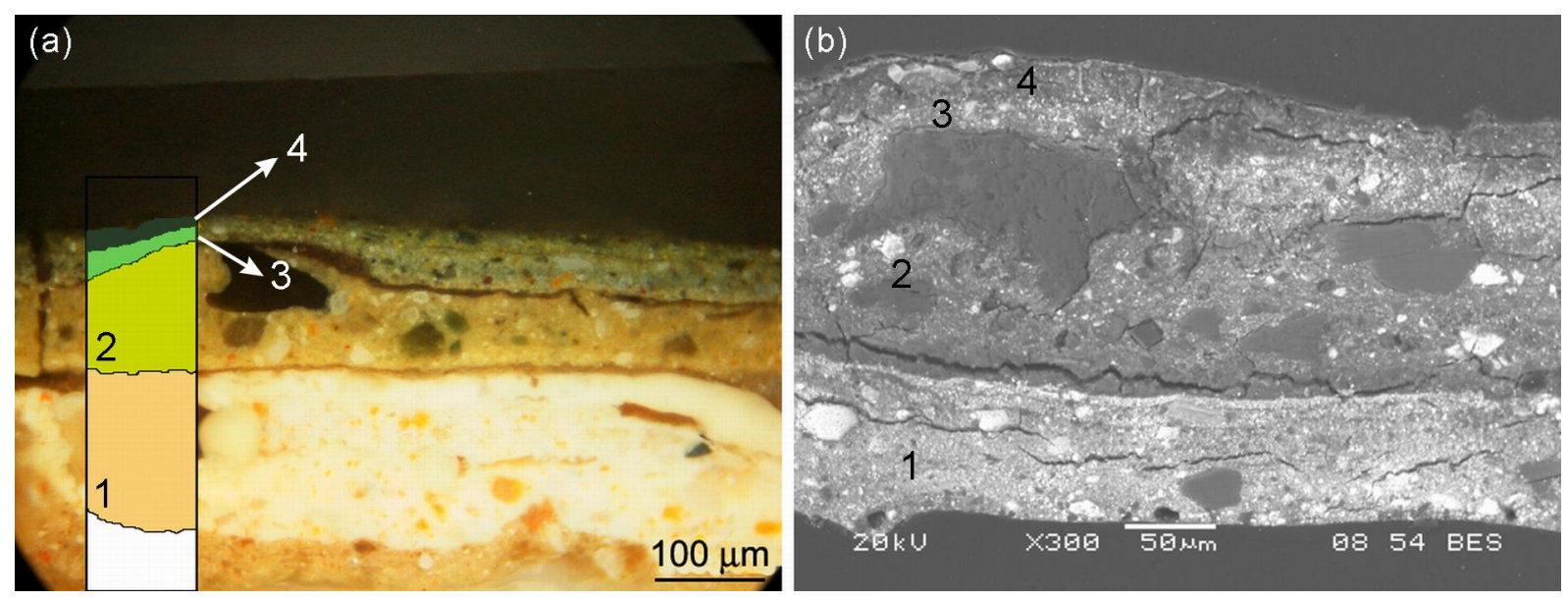

Fig. 3: Cross section with blackened surfaces observed under optical (a) and electron microscope (b) back scattered electrons. 
In the samples less influenced by the heat, the main components of the light green layers were identified by Raman spectroscopy as celadonite, goethite and lead white. The green pigment characterized in the Raman spectra (Fig. 4) by 272, 389, 543, $701 \mathrm{~cm}^{-1}$ lines was attributed to celadonite. This mineral of approximate composition $\mathrm{K}\left[\left(\mathrm{Al}, \mathrm{Fe}^{3+}\right),\left(\mathrm{Fe}^{2+}, \mathrm{Mg}\right)\right]\left(\mathrm{AlSi}_{3}, \mathrm{Si}_{4}\right) \mathrm{O}_{10}(\mathrm{OH})_{2}$ is one of the principal green clay minerals belonging to the green earth class. As demonstrated by Ospitali et al. [10], celadonite can be distinguished from glauconite on the basis of the medium intensity Raman line occurring in the 272-279 and 263-266 $\mathrm{cm}^{-1}$ range for celadonite and glauconite, respectively. Other differences were observed in the $\mathrm{OH}$ stretching region, which was probed using a green excitation line $(532 \mathrm{~nm})$. Green earths are reported to be stable up to $500^{\circ} \mathrm{C}$; then a possible turning into brown is observed, even if the specific thermal decomposition mechanisms are not fully known [11].

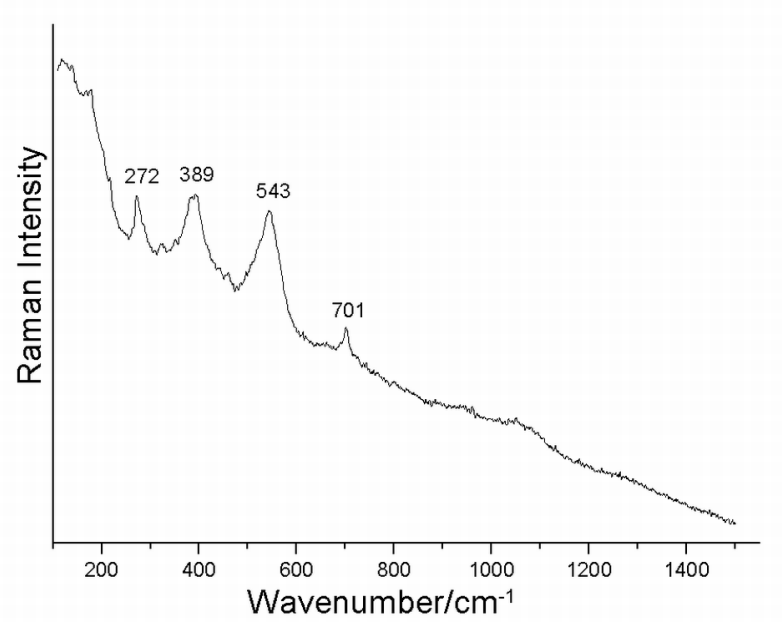

Fig. 4: Raman spectrum of light green particles, present in the inner layers in blackened samples, showing lines attributable to celadonite.

The external dark green layers (3 and 4 in Fig. 3) did not resemble the composition of the deeper ones. The spectra recorded on the bluish-green areas exhibited the Raman lines of Prussian blue, observed at 276, 532, $2094,2150 \mathrm{~cm}^{-1}$, together with lines at 988 and $1050 \mathrm{~cm}^{-1}$ due to sulphate and carbonate stretching modes of barite, and lead white, respectively (Fig. 5a). The identification of the Prussian blue was surprising as no clearly distinct blue areas were visible under the optical microscope. An example of the spectrum acquired on the same dark green layer is shown in Fig. 5b, which highlights the presence of chrome yellow although no yellow particles were visible. 

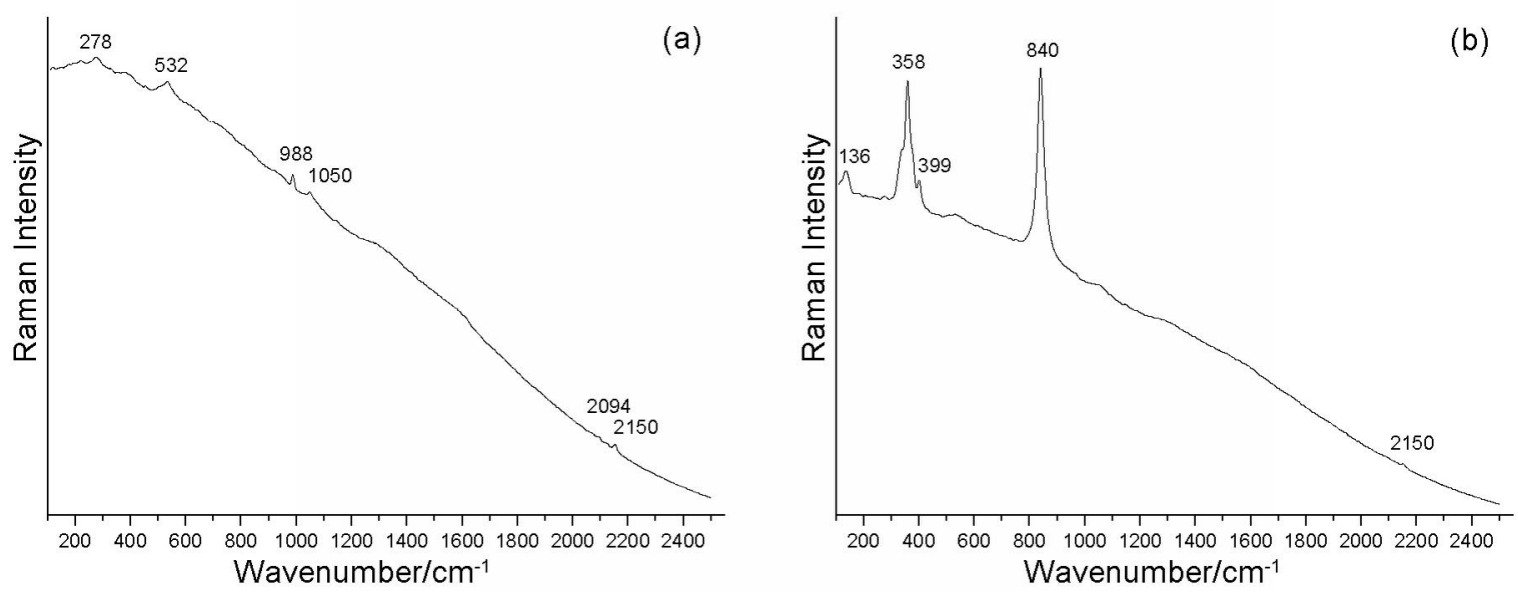

Fig. 5: Raman spectra, acquired on the external dark green layers of blackened samples, showing: (a) lines attributable to Prussian blue, lead white and barite, (b) lines attributable to chrome yellow.

Raman features at $138,358,399,840 \mathrm{~cm}^{-1}$ could be attributed to $\mathrm{PbCrO}_{4}$, also known as chrome yellow, a lemon yellow pigment discovered at the beginning of the $19^{\text {th }}$ century and introduced onto the market in 1809 . Its main Raman peak $\left(\mathrm{CrO}_{4}{ }^{2-}\right)$ is positioned from 820 to $840 \mathrm{~cm}^{-1}$ according to the pigment hue: for the orange hue, it appears at lower Raman shifts probably due to the presence of $\mathrm{PbO}$ in crystal lattice, while for the yellow hue, it is shifted to higher ones. Red and yellow ochres were also detected in layer 3, in small coloured grains. FTIR analysis confirmed Prussian blue, lead white and barite. Chrome yellow was not detected by FTIR as it was probably present in low concentrations.

FTIR spectra collected on the coloured layers exhibited the absorption bands of a blend composed of a siccative oil and lead white. The interaction of oil and lead compounds can lead to saponification, given that cerussite has a lower tendency to saponification than hydrocerussite. Hence, the microstructure of these layers varied from areas mainly composed of lead compounds, areas mainly composed of oil, and areas where a good mix had been produced by extended grinding and stirring.

The absorption pattern of the FTIR spectra thus depended on the point of sampling. What changed from one spectrum to another was the intensity ratio between peaks that could be attributed to oil, and peaks due to lead white. The spectrum recorded on a sample from the base of a column, displayed the following peaks due to oil - 2927, 2854, 1738, $1707,1176,1103 \mathrm{~cm}^{-1}$; due to lead white $-\mathrm{v}(\mathrm{OH})$ at $3538 \mathrm{~cm}^{-1}, v_{\mathrm{as}+\mathrm{s}}\left(\mathrm{CO}_{3}{ }^{2-}\right)$ at $1411+1044 \mathrm{~cm}^{-1}, \mathrm{CO}_{3}{ }^{2-}$ rocking at 680 $\mathrm{cm}^{-1}$, while the peak at $1527 \mathrm{~cm}^{-1}$ is due to saponified groups. The peak of lead carboxylate ranged from 1514 to 1557 $\mathrm{cm}^{-1}$ most likely due to the contribution of fatty acids such as azelaic, stearic and palmitic. The intensity ratio between 
the peaks at $1738,1707 \mathrm{~cm}^{-1}$ and the lead carboxylate one was variable, however the peak at $1738 \mathrm{~cm}^{-1}$ of ester carbonyl was always present.

A completely different situation was noted in the spectra, acquired on the brownish oily substances, sampled from the blackened stucco surfaces attributed to the partially decomposed and heat-affected siccative oil. The thermal degradation of linseed oil starts gradually from $100-300{ }^{\circ} \mathrm{C}$, and reaches its maximum at $300-600{ }^{\circ} \mathrm{C}$. At temperatures above $100{ }^{\circ} \mathrm{C}$, the peroxide groups decompose with the formation of radicals whose reactions with double bonds give rise to cross-linking. At the same time the secondary process of fragmentation takes place [12]. Glycerol moieties are released and disappear in the form of acrolein starting from $300^{\circ} \mathrm{C}$. Consequently, in the FTIR spectra, the absorption band due to $v(\mathrm{C}=\mathrm{O})_{\text {ester }}$ at $1738 \mathrm{~cm}^{-1}$ decreases.

The spectra of the black oily substance (Fig. 6) can be described as follows. The absorption bands at 3400 and $1737 \mathrm{~cm}^{-}$ ${ }^{1}$ due to alcohol/hydroperoxide and ester groups, respectively, are nearly absent and the band at $1707 \mathrm{~cm}^{-1}$ is of low intensity, while the band of lead carboxylate is still present. In fact, the lead salts of aliphatic acids such as lead palmitate and stearate have been reported to decompose in a higher temperature range $\left(300-500{ }^{\circ} \mathrm{C}\right)$. In addition, the spectra do not exhibit the band at $3536 \mathrm{~cm}^{-1}$ due to $v(\mathrm{OH})$ of lead white, most likely due to the thermal decomposition of this pigment which starts by de-hydroxylation at $260{ }^{\circ} \mathrm{C}[13]$. The weak band still present at around $838 \mathrm{~cm}^{-1}$ was assigned to $\mathrm{C}-\mathrm{O}$ vibration in lead carbonate. Two forms of lead oxide were also ascertained by X-ray diffraction: litharge and massicot, which coexist in the range 320 and $500{ }^{\circ} \mathrm{C}[14]$.

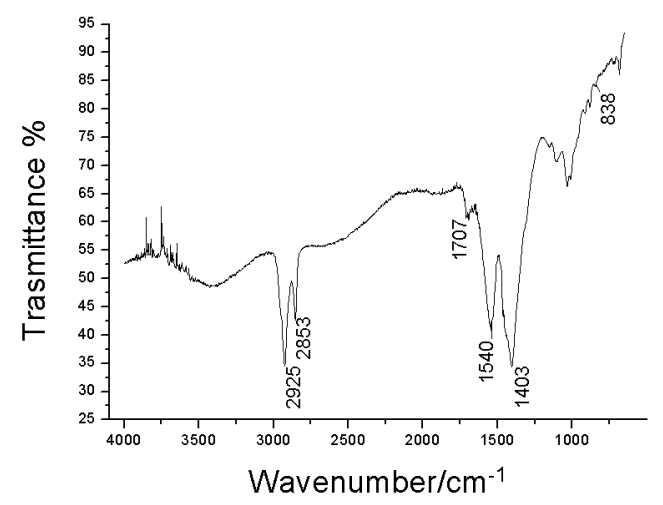

Fig. 6: FTIR spectrum of the black oily substance sampled from a blackened stucco surface. 
A strong band centred at $2091 \mathrm{~cm}^{-1}$ (CN stretching of Prussian blue) was evident only in the spectra of the samples not affected by heat: Prussian blue decomposes at around $220{ }^{\circ} \mathrm{C}$ to yield amorphous ferric oxide of black colour [15]. In several spectra of the blackened surface, the presence of barite (decomposition temperature above $1400{ }^{\circ} \mathrm{C}$ ) was ascertained. These findings suggest that the temperatures of the stucco surfaces reached during the fire, at least locally, were in the range of $300-500{ }^{\circ} \mathrm{C}$. It is known from historical records that the fire was contained in the west corner of the Hall; hence the action of the heat was most probably very different from point to point.

\section{Discussion}

Mixed colours were prepared industrially starting from the $18^{\text {th }}$ century $[16,17,18]$. Unlike a colour mixed on an artist's palette, these industrially-made colours were blended so that the individual components cannot be distinguished microscopically. Chrome green, sold to the artists under different names, is often reported as a mixture of Prussian blue with a paste of barites, china clay and chrome yellow [19].

Because of its excellent hiding power and low cost, chrome green had a great success. Industrially prepared, it was probably introduced in the first quarter of the $19^{\text {th }}$ century, and certainly after the first documented use of yellow chrome in a painting by Thomas Lawrence dated to 1810. Edwards et al. [20] found a green of a similar composition, referred to as Comper green, in a $19^{\text {th }}$ century church decoration. Rosi et al. [21] also report on chrome green, mixed with barite, in $19^{\text {th }}$ century wall paintings. The authors attribute barite to the impurity of chrome yellow, however in our opinion the painter could have used industrially prepared pigment, which included barite in the original recipe as reported by Gettens.

The presence of barite and chrome yellow, and the fact that no blue or yellow particles were identified during our examination, corroborate the thesis that the green layers observed were prepared with such a mixing formula. The costeffectiveness and the possibility of covering large areas with the tint of the ready-made colour might make it a better choice over the more laborious hand mixing. The use of the green hue that gives an earthy tone was identified only on those elements of the column's base which alternate with the gilt elements. The mixture of green earth and yellow ochre was later repainted with a chrome green blend.

The pattern of alternating green painted fillets and gilt mouldings created a play of light and shadow, which was totally lost due to the consequences of the heat developed from the combustion of the wooden hall roof. 


\section{Conclusions}

Detailed analyses of the gilt samples together with the altered finishes enabled the decorative pattern to be reconstructed of the column bases in the Hall of Caryatides located in the Royal Palace in Milan. This consisted in alternate green and gilt mouldings with a chiaroscuro effect. The blackened layers were originally of a green colour. Two distinct applications were distinguished: green earth with yellow ochre, probably used in the original finishes, and chrome green applied during later over-painting. Both pigments produced an earthy tone, which was probably used to create the semblance of a bronze surface.

The gold leaves exhibited an orange ground based on lead white with minium or ochres, bound with siccative oil. The tone of the blackened surfaces is attributed to a partial combustion of the oil used as a binder and to the thermal decomposition of pigments present in the finishes.

The use of cold colours in combination with gold leaves is quite unusual, especially as regards Italian style of ornamental patterns, and is possibly a reflection of middle-European $18^{\text {th }}$ century taste, which preferred cold hues to warm ones.

\section{References}

[1] D.V. Thompson, The practice of tempera painting, Dover, New York, 1962.

[2] M.P. Merrifield, Medieval and renaissance treatises on the arts of painting, Dover, New York, 1967.

[3] I.C.A. Sandu, M.H. de Sá, M.C. Pereirac, Ancient 'gilded' art objects from European cultural heritage: a review on different scales of characterization, Surf. Interface Anal. 43 (2011) 1134-1151.

[4] L. Rampazzi, B. Rizzo, C. Colombo, C. Conti, M. Realini, U. Bartolucci, M.P. Colombini, A. Spiriti, L. Facchin, The stucco decorations from St. Lorenzo in Laino: the materials and the techniques employed by the "Magistri Comacini”, Anal. Chim. Acta 630, 1, (2008) 91-100.

[5] A. Sansonetti, J. Striova, D. Biondelli, E.M. Castellucci, Colored grounds of gilt stucco surfaces as analyzed by a combined microscopic, spectroscopic and elemental analytical approach, Anal. Bioanal. Chem. 397 (2010) 2667-2676.

[6] D. Gulotta, S. Goidanich, M. Bertoldi, S. Bortolotto, L. Toniolo Gildings and false gildings of the baroque age: characterization and conservation problems, Archaeometry 54, 5 (2012) 940-954.

[7] M.A. Fedrigo, M. Favaro, P. Traldi, Applications of mass spectrometry in cultural heritage: identification of ligands employed for mordant gilding, Rapid. Commun. Mass Spectrom. 14, 23, (2000) 2203-2209.

[8] I.M. Bell, R.J.H. Clark, P.J. Gibbs, Raman spectroscopic library of natural and synthetic pigments (pre- $\approx 1850$ AD), Spectrochim. Acta A 53 (1997) 2159-2179.

[9] D.L.A. de Faria, S.V. Silva, M.T. de Oliveira Raman microspectroscopy of some iron oxides and oxyhydroxides, J. Raman Spectrosc. 28, 11 (1997) 873-878. 
[10] F. Ospitali, D. Bersani, G. Di Lonardo, P.P. Lottici, 'Green earths': vibrational and elemental characterization of glauconites, celadonites and historical pigments, J. Raman Spectrosc. 39, 8 (2008) 1066-1073.

[11] S. Rickerby, Heat alterations to pigments painted in the fresco technique, The Conservator, 15, 1, (1991) 39-44.

[12] M. Lazzari, O. Chiantore, Drying and oxidative degradation of linseed oil, Polym. Degrad. Stabil. 65, 2 (1999) 303-313.

[13] N.S. Cohen, M. Odlyha, R. Campana, G.M. Foster, Dosimetry of paintings: determination of the degree of chemical change in museum exposed test paintings (lead white tempera) by thermal analysis and infrared spectroscopy, Thermochim. Acta, 365, 1/2 (2000) 45-52.

[14] S. Aze, J.M Vallet, V. Detalle, O. Grauby, A. Baronnet, Chromatic alterations of red lead pigments in artworks: a review, Phase Transitions, 81, (2008) 145-154.

[15] Allen JF, Bonnette AK J Thermal decomposition of Prussian blue: Isotopic labelling with Mössbauer-inactive Fe56, Inorg. Nucl. Chem. 36 (1974) 1011-1016.

[16] C. Alderson, Re-creating a 19th century Paint Pallette, Bulletin of the Association for Preservation Technology: Decorative Finishes 16, 1 (1984) 47-56.

[17] R.J. Gettens, G.L. Stout, Pigments materials. A short encyclopaedia, Dover, London (1966).

[18] Artists' Pigments: A Handbook of Their History and Characteristics, Voll.1,2,3,4, Washington, National Gallery of Art, 1986-2012.

[19] J. Winter, in: E.W. Fitzhugh (Ed.), Artists’ Pigments, vol. 3, Oxford University Press, Washington, 143-155, 1997.

[20] H.G.M. Edwards, R. Wolstenholme, Wilkinson DS, Brooke C, Pepper M Raman spectroscopic analysis of the enigmatic Comper pigments, Anal. Bioanal. Chem. 387, (2007) 2255-2262.

[21] F. Rosi, C. Miliani, I. Borgia, B. Brunetti, A. Sgamellotti, Identification of nineteenth century blue and green pigments by in situ x ray fluorescence and microRaman spectroscopy, J. Raman Spectrosc. 35 (2004) 610-615. 